\title{
CUIDAR DA EDUCAÇÃO, DA CULTURA E DE SI: HORIZONTES DE UMA EXPERIÊNCIA DE RESGATE DA CULTURA POPULAR NA ESCOLA
}

\author{
TAKING CARE OF EDUCATION, OF CULTURE AND OF ONESELF: THE \\ HORIZONS OF AN EXPERIENCE THAT RESCUED POPULAR CULTURE AT \\ SCHOOL
}

Roberta V. Leite

Miguel Mahfoud ${ }^{* *}$

Leite RV, Mahfoud M. Cuidar da educação, da cultura e de si: horizontes de uma experiência de resgate da cultura popular na escola. Rev Bras Crescimento Desenvolv Hum 2007; 17(2):74-86.

\begin{abstract}
Resumo: Sob a ótica da Psicologia da Cultura, objetiva-se compreender os fundamentos de uma prática educativa de resgate da cultura popular no âmbito escolar como forma de contribuir para a consideração do nexo educação e cultura. O contexto investigado é Morro Vermelho, comunidade rural de Caeté/MG marcada pela vitalidade de suas tradições. Realizou-se entrevista semi-estruturada com a diretora da Escola Municipal do vilarejo, principal idealizadora do projeto que buscou transformar a relação entre a escola e a cultura local. Na análise fenomenológica dos dados, buscou-se apreender o dinamismo da consciência enquanto esta confere significados às vivências. Como resultados, encontraram-se duas categorias representativas das motivações que nortearam a iniciativa pioneira: a) cuidar da cultura que reconhece como constituinte de si; b) fomentar a participação das crianças na cultura como forma de cuidado com o seu presente e com o seu futuro. Os resultados apontam a proeminência da primeira categoria, mostrando porque fazer da cultura popular fonte da educação é tomado como dever da escola e levando à constatação da centralidade da pessoa do educador na revitalização da relação entre educação escolar e cultura popular. É o reconhecimento pessoal do enraizamento na tradição de que é herdeiro que lhe permite agir favorecendo tanto o fortalecimento da cultura quanto a recuperação da legitimidade da prática educativa realizada na instituição escolar.
\end{abstract}

Palavras-chave: Educação escolar. Cultura popular. Fenomenologia. Pessoa.

\section{INTRODUÇÃO}

A reflexão sobre educação passa, necessariamente, pela consideração da cultura, uma vez que a relação entre ambas é íntima: toda educação transmite seleções e reorganizações ativas dos saberes e materiais constituintes da cultura, e esta, por sua vez, somente se realiza, mantém-se viva, através do esforço educativo que a perpetua ${ }^{1}$.

Entretanto, na contemporaneidade, essa relação orgânica encontra-se abalada pela ascensão do discurso pós-moderno que reivindica o di- reito de levantar dúvidas sobre a pertinência e a consistência de toda e qualquer proposta estabelecida, tomando a mudança e a utilidade momentânea como critérios supremos de avaliação. Segundo Grygiel ${ }^{2}$, trata-se de um aprisionamento da civilização ocidental in saeculo, isto é, de uma apologia ao corruptível que tende a ligar o homem apenas a coisas continuamente novas, soluções provisórias que lhe conferem a falsa impressão de ser capaz de estruturar a vida a partir de fragmentos da realidade. Nesse contexto, a cultura é enfraquecida pelo constante questionamento da

Graduanda do Curso de Psicologia da Universidade Federal de Minas Gerais

** Professor Doutor da Universidade Federal de Minas Gerais. Responsável pela correspondência. Departamento de Psicologia. Faculdade de Filosofia e Ciências Humanas. Av. Antônio Carlos, 6.627 - Campus Pampulha 31270-901 - Belo Horizonte (MG). E-mail: mmahfoud@yahoo.com 
validade de suas diretrizes e do princípio de autoridade em que se assenta.

Como corolário, assiste-se à deslegitimação das práticas educativas pois, em última instância, a adesão a esse processo traz consigo a impossibilidade de afirmar o valor intrínseco do que é transmitido ou mesmo da atividade formadora em si. Sem o reconhecimento da importância da cultura não se sabe mais o quê e para quê ensinar, a educação simplesmente não pode ser justificada. De fato, para Hanna Arendt ${ }^{3}$, a condição paradoxal para que aqueles que chegam ao mundo tenham alguma chance de produzir algo de novo é justamente "respeito extraordinário pelo passado" (p.244) por parte dos que têm a tarefa de apresentar-lhes esse mundo. Uma atitude essencial, que ela constata ser extremamente rara na contemporaneidade.

Está caracterizada aquela que tem sido denominada "crise da educação", a qual pede revisões urgentes das teorias e práticas pedagógicas em voga ${ }^{1,4}$. Diante desse impasse, emerge a relevância de um retorno à experiência, de um olhar que, contemplando a articulação entre educação e cultura em ato, busque colher suas características constituintes e, dessa forma, possa contribuir com as tentativas de superar a crise em questão.

Nesse sentido, inserindo-se no âmbito da Psicologia da Cultura de orientação fenomenológica $^{5}$, a experiência escolhida para análise neste trabalho constitui-se no encontro entre a educação escolar e uma cultura que pode ser tomada como típica representação da cultura popular brasileira.

Uma vez que os pesquisadores não pertencem ao contexto cultural analisado, essa pesquisa configura-se como um esforço de investigação trans-cultural. Tem-se como premissa o fato de que a diversidade entre coletividades é o resultado de expressões e configurações variadas de uma mesma estrutura humana partilhada por todos, sendo preservada, portanto, a possibilidade de penetrar em culturas alheias, teórica e praticamente, através da atenção aos seus aspectos primordiais. Nesse movimento, entende-se ser possível tanto compreender o que se nos apresenta como diferente quanto explicitar os elementos constitutivos do fenômeno em estudo ${ }^{6}$.

O contexto escolhido é Morro Vermelho, pequena comunidade rural do município de Caeté/ MG, que tem cerca de 800 habitantes e é marcada pela vitalidade e riqueza de sua tradição. Sua cultura popular é essencialmente religiosa, marcada por fortes traços barrocos ${ }^{7,8}$. Mantém celebrações seculares, como a Cavalhada ${ }^{+}$e a Encomendação das Almas $^{++}$, além de diversas outras festividades religiosas grandiosas, considerando-se as proporções do vilarejo, às quais habitantes e ex-moradores dedicam-se amplamente ao longo de todo o ano?.

As dimensões da vida encontram-se centralizadas na figura da padroeira local, Nossa Senhora de Nazareth, o que contribui para sua designação como comunidade tradicional ${ }^{10}$. Outros elementos que a caracterizam como uma comunidade tradicional são a confiança depositada nos antepassados, a abertura diante do mistério e o trabalho vivo da memória coletiva ${ }^{11,12}$.

Entendendo, com Halbwachs ${ }^{13}$, que a memória coletiva de um grupo é um "quadro de analogias" em que se destacam a permanência e a distinção em relação a outras coletividades, percebemos no vilarejo intenso empenho na transmissão da história e tradições locais e forte tendência a explicar características atuais da comunidade à luz de momentos de origem míticos. Como exemplo, tem-se o grande destaque dado pela comunidade à participação dos moradores em eventos que marcaram a história do país como a proclamação da Guerra dos Emboabas em luta pela liberdade, o conflito para a diminuição dos impostos referentes ao ouro em 1715 , e a primeira campanha de "Diretas Já", em 1983 ${ }^{14}$.

\footnotetext{
A Cavalhada é uma tradição medieval, trazida ao Brasil pelos portugueses e realizada em Morro Vermelho desde 1704, segundo o relato de seus moradores. Trata-se de uma encenação a cavalo, em que se busca representar o encontro entre cavaleiros mouros e cristãos, quando os primeiros já foram convertidos. Em Morro Vermelho, é realizada sempre no dia sete de setembro durante a festa da padroeira local, Nossa Senhora de Nazareth ${ }^{9}$.

++ A Encomendação das Almas, também de origem medieval, realiza-se em algumas madrugadas da quaresma, em que penitentes saem em cortejo às ruas cantando e rezando pelas almas do Purgatório e alertando a comunidade de que a morte chegará para todos. Acreditam que as próprias almas acompanham o cortejo e, ao seu término, os penitentes entregam as almas a Deus para que descansem junto aos outros mortos ${ }^{16}$.
} 
A sobrevivência das tradições ao longo dos séculos deve-se à educação informal, característica das comunidades tradicionais, em que pais transmitem a seus filhos o modo próprio da comunidade elaborar experiências e constituir conhecimentos significativos, de forma que as crianças compartilham e atuam no mesmo universo de sentido dos adultos. A este processo formativo somou-se, a partir de meados do século passado, o da educação formal com a instalação de uma escola pública primária no vilarejo ${ }^{14}$.

Gradativamente, a relação entre os dois modos de formação tornou-se tensa em virtude do distanciamento entre as diretrizes impostas à escola pelo governo e os valores fundantes da comunidade. Neste contexto, as professoras naturais de Morro Vermelho empenhavam-se em conciliar as culturas escolar e popular de acordo com suas próprias elaborações pessoais. Entretanto, trata-se de esforços isolados, assistemáticos e não problematizados ${ }^{15}$.

Em 2003, porém, um novo movimento surgiu: a escola propôs, oficialmente, um trabalho exclusivamente voltado para elementos das manifestações culturais da comunidade. $\mathrm{O}$ tema central foi a Charola de Nosso Senhor dos Passos Peque$n^{\mathrm{X}}$ e aos alunos coube pesquisar sua história e cânticos que são entoados na procissão, além de confeccionar réplicas da Charola que foram expostas na Secretaria de Educação na sede do município.

De certa forma dando continuidade a tal proposta, mas ampliando-a consideravelmente, em 2004 realizou-se um projeto que envolveu todas as classes da escola tendo como foco a comemoração dos 300 anos da Festa de Nossa Senhora de Nazareth. O projeto caracterizou-se pelo empenho de recuperação da relação orgânica com a cultura popular local e teve como ápice a apresentação à comunidade do material produzido pelos alunos. Neste evento, vários elementos que compõem as manifestações culturais do vilarejo estavam presentes, como a Bandeira de Nossa Senhora de Nazareth, que é reverenciada e levantada durante a Cavalhada, e o Tapete de Serragem feito no adro da Igreja para a passagem da procissão, também durante a festa da padroeira. Além disso, houve apresentação da Banda de Música Santa Cecília, que abre a apresentação da Cavalhada, e encenação da Cavalhada-Mirim ${ }^{\mathrm{XX}}$ realizada pelos alunos, de maneira que naquele momento todos os presentes faziam experiência das festas próprias de Morro Vermelho.

O objetivo do presente trabalho é apontar as motivações subjacentes à iniciativa de concretizar esse projeto, bem como colher os indícios do modo próprio desta comunidade vivenciar suas tradições e as implicações que esta proposta inovadora trouxe para a relação entre educação escolar e cultura popular. Para tanto, serão tomadas como objeto as elaborações do seu principal idealizador.

\section{Referencial Teórico-Metodológico}

Por ser o nosso propósito compreender as motivações subjacentes a uma proposta educativa original em um contexto específico através das elaborações do próprio sujeito que a empreendeu, recorremos à Fenomenologia de Edmund Husserl, pois ele mesmo compara-a a um trabalho de arqueologia, que parte daquelas vivências que se configuram como o fluxo de consciência e busca escavar a subjetividade para chegar à estrutura das diversas vivências, como elas se organizam e se manifestam ${ }^{19}$.

Tal proposta de análise das vivências busca superar aquilo que Husserl chama "atitude natural", em que o pressuposto de que sujeito e objeto são entidades distintas leva à contraposição entre o objeto em si e a sua representação na consciên-

x Charola é uma espécie de andor com o qual a imagem de Nosso Senhor dos Passos Pequeno é carregada por crianças da comunidade de Morro Vermelho no período da Quaresma. Durante a procissão, a charola, enfeitada de flores e papéis coloridos, percorre as casas do vilarejo enquanto as crianças e alguns devotos que a seguem cantam e tiram esmolas. Essa arrecadação custeia os festejos da Semana Santa ${ }^{17}$.

xx A Cavalhada-Mirim é uma representação da Cavalhada tradicional feita pelas crianças da comunidade e que integra a Festa de Nossa Senhora do Rosário. Nela, os meninos procedem exatamente como os cavaleiros da outra encenação, repetindo as mesmas falas e coreografias "montados" sobre cavalos de pau. Trata-se de uma "tradição recente", que surgiu há cerca de vinte anos como forma de integrar o interesse das crianças pela Cavalhada e de prepará-los para a assumirem quando se tornarem adultos ${ }^{18}$. 
cia do sujeito. À "atitude fenomenológica", ao invés, interessa apenas o objeto-enquanto-percebido pela consciência. Sob este prisma, dissolvese a dicotomia entre sujeito e objeto, pois ambos só podem ser concebidos em relação, e explicitase a possibilidade de conhecer o que é característico dos objetos através da análise da consciência que os apreende ${ }^{20}$.

Além de Husserl ${ }^{21}$, no que tange às contribuições teóricas da Fenomenologia, também serão consideradas neste trabalho as reflexões de Edith Stein $^{22-25}$ e Angela Ales Bello, $19,26,27$.

Tendo como pressuposto em seu trabalho de escavação da subjetividade a atitude de epochèsuspensão de juízos para a captação dos elementos essenciais constituintes do fenômeno, daquilo que se mostra à consciência ${ }^{20}$ - Husserl demonstrou que as vivências têm peculiaridades tais que revelam o ser humano como uma unidade constituída por três dimensões distintas: a corpórea, a psíquica e a espiritual ${ }^{6,27}$.

Contribuição original da Fenomenologia para a compreensão das ações do homem no mundo, a distinção entre psique e espírito pode ser melhor compreendida graças às pesquisas de Edith Stein. Segundo a filósofa, enquanto a psique é marcada pela passividade e pelo determinismo estrito, em que as vivências se sucedem causalmente, na dimensão espiritual não há elos causais e sim ligações por motivação, que se dão entre motivos percebidos pela consciência e ações da vontade que visam realizá- $\operatorname{los}^{25}$.

Aprofundando a investigação da subjetividade, Stein aponta a existência de um núcleo ou princípio identitário, o qual remete ao que é mais próprio de cada individualidade. Esse núcleo não se altera ao longo da vida, mas dá a direção para o desenvolvimento da psique e do espírito. Para ela, mesmo sendo possível não seguir o caminho indicado, a realização humana se vincularia à realização do núcleo ${ }^{22}$.

Stein $^{22}$ afirma ainda que aquilo que distingue o homem dos animais é o ser pessoa, que é justamente ser livre e espiritual. Liberdade significa que o homem pode posicionar-se no sentido de responder ao jogo de estímulos e respostas em que está imerso, dando ou não seguimento aos convites feitos por aquilo que o interpela. Isso não quer dizer que o horizonte de ação humana seja ilimitado, pois há tanto um princípio ordenador da natureza humana, que lhe confere potências e limites, quanto um senso de dever, em que a possibilidade se converte em chamado a realizar algo. Espiritualidade pessoal, por seu turno, quer dizer vigilância - o saber-se vivo que atravessa a própria vivência em ato - e abertura - que se refere tanto a esse saber originário de si, que é abertura para dentro, quanto ao saber do que é distinto do próprio eu, que é abertura para fora.

Delineia-se, assim, como a dimensão característica do ser humano liga-o, simultaneamente, ao mais íntimo de si e ao outro.

Analogamente, pode-se dizer que também a descrição fenomenológica tem essa dupla direção, pessoal e coletiva, pois dirige-se para o interior do sujeito através da análise da vida de consciência, e para a esfera inter-subjetiva, através da análise das concepções de mundo ${ }^{6}$.

Percorrendo essa segunda via de análise, Husserl cunhou o termo "mundo-da-vida"20,21, para referir-se ao contexto intersubjetivo de significação, isto é, ao "mundo histórico-cultural concreto, sedimentado intersubjetivamente em usos e costumes, saberes e valores, entre os quais se encontra a imagem do mundo elaborada pelas ciências" (Zilles ${ }^{20}$, p.144).

O mundo-da-vida é o mundo experimentado pelo homem e que inclui tanto a empiria sensível do mundo físico quanto a realidade que ele mesmo constrói, sua história, linguagem, valores... ${ }^{20,21}$

Nesse sentido, a ontologia do mundo-davida coincide com a da cultura 6 , que "é reconduzida ao seu significado profundo, constituído pela mentalidade, pela forma de orientação, pelas expressões e pelos produtos próprios de um grupo humano" (p.42). Considerando-se que sua manutenção está estritamente vinculada aos juízos e crenças daqueles que a compõem, chega-se à centralidade das pessoas na cultura, sem as quais ela não se constitui e nem sequer se pode compreendê-la.

Investigando tal relação entre pessoa e cultura, Stein ${ }^{24}$ demonstra que os bens culturais são justamente criações próprias da dimensão espiritual do ser humano, a qual permite a ele agir configurando o mundo que o rodeia de modo a constituir objetos de valor para sua formação interna. 
Stein $^{22}$ aponta para um outro fator essencial na caracterização da cultura, pois, sendo ela auto-expressão de um povo, sua análise somente está completa se se considera a modalidade de associação desse povo. Dentre as modalidades existentes, aquela que mais respeita a pessoa e se aproxima do sentido profundo da cultura, aqui apresentado, é a comunidade ${ }^{25}$, pois o que une seus membros é "a conexão profunda que nasce da força psíquica ou espiritual do indivíduo, a qual interage com aquela dos outros" (Ales Bello ${ }^{26}$, p. 168).

Mais uma vez, emerge a importância da consideração da pessoa, uma vez que a comunidade não a absorve, pelo contrário: é justamente nas manifestações subjetivas da espiritualidade pessoal que se abre a possibilidade de compreensão do que ocorre no nível objetivo comunitário ${ }^{26}$.

Ademais, contribui para tal caracterização da comunidade e da singularidade como momentos co-relatos o reconhecimento de que todo homem é um ser separado dos outros, único em seu modo de ser e, simultaneamente, um membro de uma comunidade, pois compartilha com todos os demais uma mesma natureza humana ${ }^{23}$. Como corolário, tem-se que o locus privilegiado de realização da pessoa é justamente o contexto relacional comunitário ${ }^{26}$.

Ainda sobre o que é próprio da comunidade, assim como há o núcleo da pessoa, $\operatorname{Stein}^{25}$ indica também a existência do núcleo da comunidade, o qual é constituído por aqueles membros que tomam a vivência do outro como parte da própria vida, procurando cuidar de seus caminhos e sentindo como suas as dores dele. Quanto maior for a atuação, consciente e coerente, dos sujeitos que compõem o núcleo, maior será a consistência do grupo e a confiança nela depositada por observadores externos. Inversamente, a redução do número dessas pessoas ou a sua desvinculação do contexto comunitário traz consigo o risco da fragmentação e eventual dissolução da comunidade.

Nesse ponto, a análise do que é próprio da comunidade dirige-se para a questão da educação. De fato, se a comunidade não se sustenta sem a força daqueles que a compõem, sua manutenção ao longo do tempo depende radicalmente da transmissão do que lhe é próprio, isto é, da sua cultura às gerações vindouras ${ }^{3}$.
Entretanto, por educação não se compreende somente a apresentação de heranças coletivas aos membros mais jovens. Educação em seu sentido pleno tem a ver com formação da pessoa, que inclui tanto o desenvolvimento da unidade corpo-psique-espírito, quanto a ampliação do mundo explorado e constituído pelo sujeito ${ }^{24}$.

A respeito dos desdobramentos desse processo, escreve $\operatorname{Stein}^{24}$ (p. 187):

Junto com o alimento espiritual [o espírito] recebe o estímulo para criar e formar em si mesmo; se sente solicitado a fazer que sua própria essência, que interiormente lhe plasma a forma, demonstre sua eficácia no exterior, em fatos e obras que dão testemunho dele. (...) O exercício das correspondentes capacidades práticas e criativas, como habilidades dispostas à ação, é uma parte essencial do processo formativo. Nisto consiste certamente o sentido mais profundo do trabalho escolar.

Além das contribuições próprias da Fenomenologia, que orientam as concepções de homem, cultura e educação que embasam a presente pesquisa, cabe uma breve conceitualização da dimensão específica da cultura que interessa a este trabalho, a cultura popular, bem como sumária apresentação do processo que culminou no surgimento da educação escolar.

Sobre a cultura popular, Raymond Williams (cf. Escosteguy ${ }^{28}$ ) insiste em seu caráter ordinário, compreendendo-a como a experiência vivida que se dá na interação dos sujeitos comuns com os textos e práticas da vida.

No mesmo sentido, Ecléa Bosii ${ }^{29}$ delineia cultura popular como "realidade cultural estruturada a partir de relações internas no coração da sociedade" (p.63) e, em sua discussão do tema, apresenta ainda as concepções de Gramsci e Xidieh, em que se destacam, respectivamente, seu caráter passadista e inovador e sua coesão interna, onde cada elemento tem seu papel na economia do todo.

Embora ela não tenha se dedicado especificadamente ao tema da cultura popular, é válido destacar os apontamentos de Simone Weil ${ }^{30}$ a respeito da vinculação estreita entre a pessoa e o 
meio social em que vive. Para delinear tal relação, a autora cunhou o termo "enraizamento", afirmando tratar-se de uma necessidade humana, importante e ao mesmo tempo desconhecida, que se realiza através da participação real, ativa e natural em uma coletividade.

Quanto à educação escolar, tem-se que historicamente, nas sociedades mais complexas, marcadas pela proeminência da cultura científica, assistiu-se a um processo vertiginoso de especialização do saber, fazendo com que nem as famílias, nem os demais meios humanos que cercam a pessoa pudessem oferecer-lhe as aquisições culturais tomadas como elementares em seu ambiente. A força desse processo estendeuse também a outros espaços, superando os limites das sociedades urbanas e chegando até mesmo ao âmbito das comunidades tradicionais ${ }^{31}$.

É nesse contexto que surgem instituições com a responsabilidade específica de assegurar a transmissão cultural, dentre as quais a escola se destaca como a mais típica. Segundo Modesto ${ }^{32}$ à escola foi transferida a responsabilidade pela formação integral do homem, antes pertencente à Igreja. Entretanto, esse papel não tem sido desempenhado dada a enorme cobrança da sociedade e do Estado para que se priorize o preparo profissional, reflexo da supervalorização da dimensão econômica.

\section{METODOLOGIA}

A escolha do sujeito se deu por amostragem intencional, sendo o critério de escolha a participação na idealização e implementação do projeto de resgate da cultura própria de Morro Vermelho no contexto da escola local. Desse procedimento, resultou a escolha da diretora da escola, Silvana, como sujeito desta pesquisa. Natural da comunidade, Silvana tem um histórico de participação ativa nas manifestações culturais de Morro Vermelho e, à época da realização da pesquisa, encontrava-se há dois anos à frente da direção da escola.

$\mathrm{Na}$ coleta de dados, recorreu-se a entrevista semi-estruturada, realizada em momento propício à elaboração, neste caso, durante a apresentação à comunidade do material produzido pelos alunos durante o projeto, ocorrida em 22 de outubro de 2004.

Para a análise dos dados, utilizou-se o método fenomenológico descrito por van der Leeuw $^{33}$ e Amatuzzi $^{34}$, que parte da experiência pré-reflexiva para, através da atenção às propriedades dessa experiência, chegar aos seus elementos estruturais, às suas características inerentes ou intrínsecas.

Tomando como ponto de partida os passos metodológicos propostos por van der Leeuw ${ }^{33}$, percorremos o seguinte roteiro:

1. Leitura atenta e repetida das transcrições das entrevistas;

2. Inserção na própria vida: vivência consciente e metódica das ressonâncias que o fenômeno em estudo provocou no pesquisador;

3. Suspensão da faticidade e de convicções pessoais prévias para a captação do sentido (essência) presente no que se mostra;

4. Estabelecimento de categorias iniciais em que se buscou ressaltar as conexões de sentido existentes;

5. Vivência de compreensão do fenômeno e correção contínua das análises realizadas através do retorno ao depoimento e ao que foi suspenso;

6. Exame das compreensões alcançadas em espaços coletivos (supervisão, grupo de pesquisa) e confronto com o referencial teórico-metodológico adotado;

7. Reconstrução da experiência vivida pelo sujeito visando sua apresentação a terceiros de modo a possibilitar o acesso à compreensão da vivência alcançada.

\section{RESULTADOS}

Apresentam-se duas categorias representativas, para o sujeito, dos sentidos do ato de empenhar-se na revitalização da relação entre a educação escolar e a cultura popular local.

Considerando-se que se trata de uma ação que não poderia ser compreendida apenas a partir do nível psíquico, buscou-se explicitar, em cada categoria, a dinâmica própria da dimensão espiritual, atentando para os motivos subjacentes e o vínculo motivacional entre os atos. 
Além disso, ancorando-se no referencial teórico-metodológico acima delineado, entendese que o material colhido, as elaborações que se apresentam à consciência do sujeito apreendidas pela análise de seus depoimentos orais, é fonte de conhecimento tanto dos processos internos a ele quanto do mundo que o cerca, ao qual ele dirige sua mirada. Assim, a apresentação dos vínculos motivacionais será permeada por indícios do modo próprio da comunidade de Morro Vermelho viver sua tradição e das transformações em curso na articulação entre educação escolar e cultura popular.

As categorias elaboradas são: (1) cuidar da cultura que reconhece como constituinte de si e (2) fomentar a participação das crianças na cultura como cuidado com o seu presente e o seu futuro.

\section{Cuidar da cultura que reconhece como constituinte de si}

Nesta categoria, emerge como motivo da ação de Silvana o seu envolvimento pessoal com a cultura popular. Envolvimento que passa pelo senso de pertença ao lugar e à história ("por eu ser daqui, raiz de Morro Vermelho, então, assim, eu sou apaixonada, sou apaixonada com a tradição, o folclórico, o religioso") e inclui a compreensão intelectiva da importância da tradição, tanto por sua riqueza de conteúdo, quanto por sua permanência ao longo dos séculos, o que indica o reconhecimento de seu valor por muitas outras gerações.

Além disso, tal envolvimento ressoa afetivamente indicando a unidade das dimensões da sua pessoa nessa vinculação de si às tradições locais:

E também porque é daqui, raiz daqui, né, e eu me sinto muito... eu me sinto muito feliz de ser morrovermelhense, de morar aqui, de ter essa cultura, essa tradição que veio lá de Portugal.

Esse projeto eu fiquei muito encantada, muito emocionada.

A partir da clareza quanto a tais fatores, a sua motivação descortina-se como propósito e ação intencional de não deixar morrer o que vivencia como central em si. Em suas palavras:
A escola preocupa sim de estar passando esse conhecimento para eles, para eles serem uma geração que está dentro, né, como vamos falar, estar dentro do que é nosso, dentro de uma escola que é minha, é sua, né, é uma história e a gente não pode deixar a história morrer, né, nós fazemos parte da história.

E a força de tal objetivo, que brota de um reconhecimento do próprio enraizamento na cultura em que nasceu, traz consigo uma importante implicação para a compreensão da articulação entre cultura popular e educação escolar: faz com que a educação que transmite a cultura local, com atenção à totalidade dos elementos envolvidos, seja encarada como um dever da escola.

Então eu vejo assim, a necessidade de eu estar passando o que eu aprendi para eles, né. A parte folclórica também, né, como importante dessa tradição que nós herdamos dos portugueses. Então eu vejo que eles têm que estar mesmo envolvidos, têm que ter esse conhecimento, que é a partir desse conhecimento que vai dando continuidade, que isso faz parte da nossa história e deles também, né.

E na medida que não trabalha isso fica difícil e não pode, né, jamais, a cultura não pode ficar de fora, ainda mais uma cultura tão rica que é a nossa.

A contribuição da escola é a continuidade dessa tradição que não pode acabar.

Além disso, a importância da continuidade da tradição é tal que ela entende que o cuidado com a cultura não deve se restringir à sua comunidade, e sim expandir-se também para outros lugares. Nesse sentido, o modo como os moradores do vilarejo empenham-se na vivência de sua cultura é tomado como emblemático para contextos diversos, como se a valorização dos bens próprios de cada coletividade pudesse ser recuperada a partir da observação do exemplo de Morro Vermelho. Em suas palavras:

Você quer estar tendo a participação deles [pessoas de outras escolas] porque eu tenho certeza que as crianças, a preocupação é com a 
visita das crianças, porque eles iam também gostar de saber como que no Morro, como que a escola do Morro está trabalhando a tradição. Por que não a escola deles também, não estarem também trabalhando dentro da cultura deles? E tem o modo, a forma de estar incentivando, trazendo visitas de outras escolas, estar incentivando trabalhar com a cultura local, né.

Outro fator que sobressai nessa categoria é a grande abertura para a consideração dos aspectos próprios do momento presente e suas implicações futuras. De fato, em sua reflexão sobre as configurações do contexto atual, Silvana percebe que a escola se apresenta como uma das guardiãs da cultura e sua atuação, hoje, mostra-se como imprescindível em sua manutenção.

E se a escola também não trabalha, será que daqui trezentos anos vão estar fazendo essa festa novamente? Minha preocupação também é isso. Daqui trezentos não, daqui cinqüenta, daqui cem, entendeu? Não vai chegar nem nos quinhentos anos. Daqui cinqüenta anos, como que estará o Morro Vermelho, né?

Os trechos do depoimento até aqui apresentados trazem consigo diversos indícios de como um membro típico da comunidade de Morro Vermelho vivencia suas tradições. Neste momento, dois pontos principais serão ressaltados.

O primeiro relaciona-se ao fato de Silvana usar o termo "folclore", porém não na acepção corrente de mero agregado de costumes pitorescos desvinculados da realidade cotidiana da comunidade que a vivencia. "Passar a parte folclórica" não é o mesmo que apresentar de modo caricatural as raízes distantes da sociedade urbana, como em geral se vê nas escolas brasileiras. Ao invés, ao falar em folclore, a educadora refere-se aos bens culturais únicos do seu vilarejo, às tradições que são mantidas de modo vivo em Morro Vermelho. Vivo porque a própria identidade pessoal de seus membros estrutura-se a partir da participação ativa no âmbito da cultura. A descrição que acaba de ser feita da forte vivência de enraizamento da própria Silvana atesta essas compreensões.

Essa distinção é sinal de como a comunidade em questão é capaz de tomar elementos extrínsecos, como a nomeação de certa modalidade cultural com o termo "folclore", de modo próprio. Nesse processo de diálogo com o novo, o que é vislumbrado como contribuição é redimensionado e pode ser assimilado, sem que se perca a própria referência.

$\mathrm{O}$ segundo ponto diz respeito à constante afirmação de que as tradições de Morro Vermelho são heranças de uma outra cultura, a portuguesa. Mais uma vez, o que está implícito aqui se choca frontalmente com práticas e discursos estabelecidos, que tendem a taxar de alienação a adesão àquilo que vem de fora, ao que tem suas raízes em outro lugar. Entretanto, para a comunidade em estudo, o reconhecimento de seus afluentes não é sinal de perda de identidade, pelo contrário, é afirmação radical desta, a qual visa não perder nada que diz respeito à própria história, o que inclui uma preocupação ampla com suas próprias origens.

\section{Fomentar a participação das crianças na cultura como cuidado com o seu presente e o seu futuro}

Além da preocupação com a continuidade da tradição, o empenho de Silvana em resgatar a relação entre escola e cultura popular revela uma atenção especial com os sujeitos alvo de seu esforço educativo: as crianças.

Nesse sentido, a sua ação tem como motivo uma observação acurada de aspectos que são próprios do desenvolvimento, levando-a a constatar que "você vai crescendo, você vai querendo saber das coisas", isto é, há um "interesse natural" dos pequenos por aquilo que os rodeia. $\mathrm{E}$, se o que rodeia as crianças na comunidade de Morro Vermelho é a cultura popular, o desdobramento esperado seria o de um razoável envolvimento de todos, desde pequenos, nas manifestações culturais do vilarejo.

Entretanto, nas observações da coordenadora, não é isso que se dá atualmente: ao interesse infantil segue-se um preocupante afastamento dos jovens do âmbito da tradição. Preocupante porque este afastamento estaria associado à adesão a influências encaradas como nocivas, como a das drogas, que há poucos anos não che- 
gavam até a comunidade e que hoje se fazem presentes pelo maior intercâmbio com o meio urbano.

Eu tenho visto nessa geração agora que eles não têm essa intimidade [com a tradição], esse gosto que nós temos e que eu vejo que os mais velhos têm.

Os meninos de hoje, os rapazinhos não estão envolvidos mesmo. Eu tenho irmãos e eles participam assim, gostam da farra, entendeu?

Não sou contra quem vai para bar, que bebe, acho que cada um tem a sua forma de se distrair, mas o mais triste de hoje é que Morro Vermelho não tinha drogas, né, as pessoas usuários e hoje aqui tem.

Para ela, a contradição entre o interesse dos pequenos e o distanciamento dos jovens justifica-se no fato dos últimos não terem sido adequadamente estimulados a permanecerem envolvidos com as tradições. E tal concepção de que "se estivesse trabalhando antes, de repente não teria ainda [as drogas]" fomenta a motivação de preservar o incipiente gosto pela cultura popular manifesto pelas crianças através também da educação escolar.

Desse modo, o seu empenho em revitalizar a relação entre escola e cultura local seria então uma forma de cuidar tanto do presente dos alunos, do que eles são hoje, quanto do seu futuro, preservando o seu desenvolvimento das influências "nocivas" que certamente receberão.

E é preocupação sim porque eu vejo hoje as drogas, né, a gente tem que estar tirando, desviando esses meninos dessa parte, porque eles são crianças sim, mas um dia vão virar rapazes e eles estarem interessados na cultura, estarem trabalhando dentro da cultura, participando em setembro, da semana santa, eles estão dentro de uma cultura que não anuncia a eles outros interesses, né. É esse lado também.

Esse elo motivacional tem em seu bojo implicações do modo como Silvana concebe e vivencia a educação, a cultura e a relação entre ambas. Como exemplo, tem-se a sua compreensão de que a educação fornecida pela escola tem como meta não apenas transmitir certo tipo de conhecimentos, mas principalmente formar integralmente pessoas que sejam cidadãos hoje e amanhã, participativos no meio em que estão inseridos e não "desviados" para aqueles interesses que ela entende serem prejudiciais ao desenvolvimento.

A garra é porque eu acho assim que a escola tem que estar preocupada sim com os cidadãos de hoje, com o futuro (...), para eles crescerem cidadãos verdadeiros de Morro Vermelho participativos, né.

Sobre o que é próprio dos processos comunitários e que pode ser colhido a partir do que se apresenta à consciência de Silvana, destaca-se que a decisão da educadora de valorizar no processo educativo o modo peculiar às crianças de inserção na cultura é indicativa do movimento coletivo de acolhida da iniciativa dos mais novos e da forma que eles encontram de participar.

A princípio, este processo parece entrar em contradição com o que a mentalidade comum espera ver nas coletividades marcadamente tradicionais, isto é, a imposição de preceitos e a limitação da liberdade e expressão individuais. Entretanto, o posicionamento de abrir espaço para que cada geração participe e contribua a seu modo mostra-se, em última instância, muito mais coerente com a proposta de manutenção do contexto tradicional, uma vez que essa manutenção depende radicalmente da adesão e do trabalho empenhado das novas gerações.

Outros trechos do depoimento tornam isso ainda mais claro:

Eles [os alunos] que enfeitaram os cavalinhos, vieram hoje também para poder estar ajudando a ornamentar a escola... Porque isso, não fui eu que chamei não, eles é que vieram por vontade deles.

As mães vieram e eles também vieram e me pediram: "posso ajudar?" Pintaram os muros e está cheio de rabiscos, tudo, porque são deles e eu não quis nem passar segunda mão, não, vou deixar dessa forma porque foram as mãos dos alunos. 
Um segundo ponto de relevo para o tema em foco é o fato de que o cuidado com o desenvolvimento dos alunos através de sua inserção no âmbito da cultura já está dando resultados, visíveis tanto na maior participação das crianças nas festas do lugar: "esse ano, assim, eu fiquei encantadíssima com os meninos acompanhando a charola, eles é que cantaram, né"; quanto no envolvimento da comunidade no projeto sobre os 300 anos da Festa de Nossa Senhora de Nazareth, que então era realizado na escola:

A comunidade toda envolveu, a comunidade toda do Morro, então não foi só a escola, só os alunos, foi a comunidade, mães que vieram aqui para ajudar a gente na limpeza, na ornamentação (...), pessoas de fora também.

\section{DISCUSSÃO DOS RESULTADOS}

Nas categorias encontradas, "cuidar da cultura que reconhece como constituinte de si" e "fomentar a participação das crianças na cultura como cuidado com o seu presente e o seu futuro", é possível observar que os vínculos motivacionais partem de uma atenção à totalidade dos fatores envolvidos, com cuidado especial para as configurações do contexto atual, e se ligam tendo como meta a concretização de um projeto coerente com o que é percebido no mundo e em si.

Dentre os motivos presentes no depoimento, o que desponta com mais força é o reconhecimento de Silvana da unidade que há entre a sua pessoa e a cultura própria de Morro Vermelho. É esse reconhecimento que embasa os demais motivos, de modo que a primeira categoria revela a sua proeminência, atestando o caráter mobilizador e comprometido da experiência enraizada, tal como intuído por Weil ${ }^{30}$.

Descortina-se, assim, a centralidade da pessoa da educadora para a compreensão de sua iniciativa de revitalização da relação entre educação escolar e cultura popular. A análise empreendida demonstra que a sua ação tem como fundamento a clareza quanto ao papel da cultura na constituição de si e, como motivação promover sua real continuidade através do empenho em preservar nas crianças o gosto pela tradição.
Por meio da articulação das categorias, percebe-se ainda que o cuidado com a cultura e o cuidado com as pessoas que dela fazem parte são movimentos intrinsecamente relacionados: não há continuidade da cultura sem mobilização e consideração da pessoa e não há desenvolvimento desta fora do contexto cultural de sua formação. Esses resultados mostram-se condizentes com as reflexões de Stein ${ }^{22,23,24,25}$ e Ales Bello ${ }^{6,19,26,27}$, acerca da indissociabilidade entre pessoa e cultura.

Considerando-se ainda os apontamentos de Grygiel $^{2}$ e a descrição da atual "crise da educação" feita por Forquin ${ }^{1}$ e Faria Filho et al. ${ }^{4}$, em que se explicita como o esforço de ensino encontra-se abalado pela dificuldade de afirmação do valor de suas propostas, a análise da vivência de Silvana aponta para um outro horizonte ao indicar como o vigor do entrelaçamento entre pessoa, cultura e comunidade contribui para a revitalização do processo educativo.

De fato, os resultados mostram que no nível de reconhecimento vivencial em que se percebe o próprio enraizamento na cultura, o discurso da deslegitimação da educação simplesmente perde sentido. Se a cultura é vislumbrada como fundamental na formação pessoal, a importância de transmiti-la (não de qualquer modo, mas de forma a mantê-la viva) é uma implicação decorrente, é mesmo um dever das instituições responsáveis pelo ensino, um dever que está acima das discussões frequentemente encontradas na contemporaneidade que pretendem relativizar e esvaziar o valor do empenho de formação humana.

Quanto aos processos gerais da comunidade, foi possível apreender o quanto a vivência da tradição presente em Morro Vermelho inscreve-se em um horizonte amplo, distinto do vulgarmente esperado. Do depoimento de um de seus membros, vislumbrou-se como a tradição nessa comunidade busca dar conta de todas as dimensões da existência e guarda especial atenção ao passado, encarnado em suas origens e percursos históricos, e deposita sua esperança no futuro, representado pelas novas gerações.

Além disso, a clareza quanto ao fundamento motivacional e à sua inserção num contexto de vivência cultural tão intensa permite afirmar que o projeto empreendido pela Escola Municipal 
de Morro Vermelho significa um rompimento com a tendência atual, descrita por Modesto ${ }^{32}$, de fragmentação e priorização extrema de uma única faceta da vida observada nos ambientes formais de ensino. De fato, compreende-se que essa escola deu um importante passo no sentido de recuperar sua função originária ao aceitar o desafio de promover a formação integral de seus alunos sem desconsiderar seu nexo de pertença à comunidade e ao inscrever-se, simultaneamente, no processo de manutenção do que é próprio a esta representação da cultura popular brasileira, dando sua contribuição peculiar ao esforço coletivo pela "continuidade da tradição".

\section{CONCLUSÃO}

A partir da investigação de uma experiência de resgate da cultura popular no contexto escolar e através da análise do depoimento de sua principal idealizadora, chega-se à conclusão de que é o reconhecimento da vinculação da sua pessoa à tradição herdada e o posicionamento pessoal que visa realizar a própria estrutura que permitem à educadora agir favorecendo tanto o fortalecimento da cultura popular de sua comunidade quanto a recuperação da legitimidade da prática educativa levada a cabo na instituição escolar.

A observação e a análise apurada de um contexto cultural e comunitário tão diverso daquele em que a maior parte da civilização ocidental está imersa traz consigo algumas provocações:

A primeira delas é um chamado a reconsiderar o modo como se tem concebido e relacio- nado com a cultura, pois os homens do nosso tempo muitas vezes têm se esquecido da centralidade de sua herança cultural em sua constituição como seres humanos e em seus esforços por deixar algum legado às gerações vindouras através da educação.

A este, soma-se um alerta ainda mais direto, aos educadores, para que re-avaliem a forma como se relacionam com o conteúdo do ensino. Se eles próprios não reconhecem pessoalmente o valor daquilo que transmitem, como querer que outros o façam?

Em terceiro lugar e especialmente, a vivência de Silvana incita os pesquisadores a tratar questões amplas da esfera social, como a cultura popular e a educação escolar, sem jamais esquecer o horizonte das pessoas nelas inseridas. A riqueza que se pôde apreender das elaborações dessa educadora, atestando como é possível conhecer o mundo através dos sujeitos nele inseridos, convoca a buscar considerar sempre a pessoa e a forma como ela concebe e age em relação à realidade que vivencia.

Por fim, cabe ressaltar que, nascida do interesse em compreender a articulação entre educação escolar e cultura popular, sem perder de vista as particularidades do contexto escolhido para análise, esta pesquisa conclui-se como um testemunho de que uma relação autêntica e orgânica entre escola e cultura local não é apenas possível, como real. A investigação da experiência de Morro Vermelho documenta fundamentos motivacionais, caminhos e implicações de um esforço que visa a superar os entraves contemporâneos à formação integral da pessoa.

\begin{abstract}
Supported by Culture Psychology, the present study aims to understand the principles of a new educational practice that rescues popular culture in the school scope as a way to contribute to the consideration of the nexus between education and culture. The investigated context is Morro Vermelho, an agricultural community in the city of Caeté, state of Minas Gerais, which is known for the vitality of its traditions. A semi-structured interview was conducted with the principal of the community's municipal school. She is the main idealizer of the project that aimed to transform the relationship between the school and the local culture. In the phenomenological data analysis, the focus was on the apprehension of the dynamism of conscience as it gives meaning to life experiences. Concerning the results, two categories that represent the motivations that guided that pioneering initiative were found: a) to take care of the culture that one recognizes as a part of oneself; b) to foster children's participation in culture as a way of taking care of their present and future. The results reveal the prominence of
\end{abstract}


the first category, showing the reason why making popular culture become a source of education is taken as the school's obligation, and leading to the confirmation of the educator's importance in the revival of the relationship between school education and popular culture. It is the personal acknowledgement of the enrootedness in the tradition of which one is an heir that allows one to act favoring both the strengthening of culture and the recovery of the legitimacy of the educational practice that happens at the scholastic institution.

Key words: School education. Popular culture. Phenomenology. Person.

\section{REFERENCIAS}

1. Forquin J C. Escola e cultura: as bases sociais e epistemológicas do conhecimento escolar. Porto Alegre: Artes Médicas; 1993.

2. Grygiel S. L'uscita dalla caverna e la salita al Monte Moria: saggio su natura e civiltà. Il Nuovo Areopago 2002;19(2/3):25-61.

3. Arendt H. Entre o passado e o futuro. $5^{\text {nd }} \mathrm{ed}$. São Paulo: Perspectiva; 2000.

4. Faria Filho LM, Gonçalves IA, Vidal DG, Paulilo AL. A cultura escolar como categoria de análise e como campo de investigação na história da educação brasileira. Educação e Pesquisa [periódico online] 2004; Jan-Abr [retirado em $10 \mathrm{dez}$ 2005]; 30(1). Disponível em: URL: <http://www.scielo.br/ scielo.php?script=sci_arttext\&pid=S1517$97022004000100008 \&$ lng=pt\&nrm=isso $>$. Acesso em: 10 dez. 2005.

5. Augras M. Psicologia e cultura: alteridade e dominação. Rio de Janeiro: Nau; 1995.

6. Bello AA. Culturas e religiões: uma leitura fenomenológica. Bauru: Edusc; 1998.

7. Mahfoud M. Empenhado na mudança do milênio: identidade, história e profecia em uma comunidade rural tradicional. Memorandum [periódico online] 2001a; Out [retirado em 12 jan 2006]; 1. Disponível em: URL: <http://www.fafich.ufmg.br/ $\sim$ memorandum/artigos01/mahfoud01.htm>.

8. Mahfoud M. Emoções e imagens sagradas em festa popular brasileira de origem barroca. In: Massimi M, Silva PJC, organizadores. Os olhos vêem pelo coração: conhecimento psicológico das paixões na história da cultura brasileira dos séculos XVI a XVII. Ribeirão Preto (SP): Hollos; 2001b. p.108-21.

9. Mahfoud M, Ribeiro S M. Experiência religiosa e enraizamento social: festa e devoção dos emigrados em visita à comunidade rural de origem. Videtur [periódico online] 1999 [retirado em 12 jan
2006]; 6. Disponível em: URL: <http:// www.hottopos.com.br/videtur6/migsim.htm>.

10. Araújo RA, Mahfoud M. A devoção a Nossa Senhora de Nazareth a partir da elaboração da experiência ontológica de moradores de uma comunidade tradicional. Memorandum [periódico online] 2004; Abr [retirado em 12 jan 2006]; 6. Disponível em: URL: <http:// www.fafich.ufmg.br/ memorandum/artigos06/ aramahfoud01.htm>.

11. Schmidt MLS, Mahfoud M. Dimensões da elaboração da experiência pessoal e coletiva em comunidades tradicionais da Estação Ecológica Juréia-Itatins. Interações 1997; 2(3):67-76.

12. Mahfoud M. Percorrendo as distâncias: memória e história. In: Hoffmann A, Bueno JLO, Massimi M, organizadores. Percorrer distâncias: um desafio para a razão humana. São Paulo: Companhia Ilimitada; 2001c. p.53-64.

13. Halbwachs M. A memória coletiva. São Paulo: Centauro; 2004.

14. Alves AP, Mahfoud M. Cultura popular e cultura escolar em Morro Vermelho. In: V Congresso de Ciências Humanas, Letras e Artes / Conifes, 2001; Ouro Preto, Brasil. Ouro Preto: UFOP, 2001. Disponível em URL: <http://www.ufop.br/ichs/conifes/anais/CMS/ cms0501.htm>.

15. Leite RV, Mahfoud M. O encontro entre cultura popular e cultura escolar a partir das elaborações de professores de uma comunidade tradicional. In: Anais do III Seminário de Pesquisa e Estudos Qualitativos e V Encontro de Fenomenologia e Análises do Existir; 2006 Jun 1-3; São Bernardo do Campo, Brasil. São Paulo: SEPQ, 2006. Disponível em: URL: <http://www.sepq.org.br/vefae/pdfs/ pmchf2.pdf $>$.

16. Mahfoud M. Encomendação das almas: mistério e mundo da vida em uma tradicional comunidade rural mineira. In: Massimi M, Mahfoud M, organizadores. Diante do 
mistério: psicologia e senso religioso. São Paulo: Loyola; 1999. p.57-67.

17. Ribeiro ACF, Mahfoud M. A importância da tradicional festa do Senhor dos Passos Pequeno para o compartilhamento de significados no mundo da vida de uma comunidade rural. In: Anais da XXXV Reunião Anual da Sociedade Brasileira de Psicologia [CD]; 2005 Out 25-28; Curitiba, Brasil. Ribeirão Preto: SBP; 2005.

18. Murta A. Barangandão arco-íris: 36 brinquedos inventados por meninos. Belo Horizonte: Lapa Cia. de Ação Cultural; 1997.

19. Bello AA. Fenomenologia e ciências humanas: psicologia, história e religião. Bauru: Edusc; 2004.

20. Zilles U. Teoria do conhecimento. $2^{\text {nd }}$ ed. Porto Alegre: Edipucrs; 1995.

21. Husserl E. A crise da humanidade européia e a filosofia. $2^{\text {nd }}$ ed. Porto Alegre: EDIPUCRS; 2002.

22. Stein E. Estructura de la persona humana. In: Stein E. Obras completas. v.IV: Escritos antropológicos y pedagógicos. Vitória: Ed. El Carmen; Madrid: Ed. de Espiritualidad; Burgos: Ed. Monte Carmelo; 2003. p.555-749.

23. Stein E. Fundamentos teóricos do labor social de formación. In: Stein E. Obras Completas. v. IV: Escritos antropológicos y pedagógicos. Vitoria: El Carmen; Madrid: Ed. de Espiritualidad; Burgos: Monte Carmelo; 2003. p.127-48.

24. Stein E. Sobre el concepto de formación. In: Stein E. Obras Completas. v. IV: Escritos antropológicos y pedagógicos. Vitoria: El Carmen; Madrid: Ed. de Espiritualidad; Burgos: Monte Carmelo; 2003. p.177-94.

25. Stein E. Contribuiciones a la fundamentación filosófica de la psicología y de las ciencias del espíritu. In: Stein E. Obras completas. v.II: Escritos filosóficos: etapa fenomenológica. Vitoria: Ed. El Carmen; Madrid: Ed. de Espiritualidad; Burgos: Ed. Monte Carmelo, 2005. p.207-520.

26. Bello AA. A fenomenologia do ser humano: traços de uma filosofia no feminino. Bauru: Edusc; 2000.

27. Bello AA. Introdução à fenomenologia. Bauru: Edusc; 2006.

28. Escosteguy AC. Os estudos culturais e a constituição de sua identidade. In: Guareschi N MF, Bruschi ME, organizadores. Psicologia social nos estudos culturais. Petropólis: Vozes; 2003. p.51-74.

29. Bosi E. Cultura de massa e cultura popular: leituras de operárias. $10^{\text {nd }}$ ed. Petróplis: Vozes; 2000.

30. Weil S. O enraizamento. In: Weil S. A condição operária e outros estudos sobre a opressão. Antologia organizada por Ecléa Bosi. $2^{\text {nd }}$ ed. Rio de Janeiro: Paz e Terra; 1996. p. 411-2.

31. Palácios J, Coll C, Marchesi A. Desenvolvimento psicológico e processos educacionais. In: Coll C, Palácios J, Marchesi A. Desenvolvimento psicológico e educação. vol I. Porto Alegre: Artes Médicas; 1995. p.325-39.

32. Modesto AL. Religião, escola e os problemas da sociedade contemporânea. In: Dayrell J, organizador. Múltiplos olhares sobre educação e cultura. Belo Horizonte: UFMG; 1996. p.77-84.

33. van der Leeuw G. Fenomenologia de la religión. México: Fondo de Cultura Económica; 1964.

34. Amatuzzi M. Por uma psicologia humana. Campinas: Alínea; 2001.

Recebido em 25/03/2007

Modificado em 21/04/2007

Aprovado em05/05/2007 